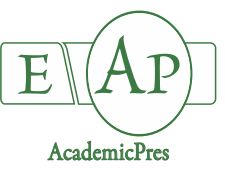

Kim SH et al. (2020)

Notulae Botanicae Horti Agrobotanici Cluj-Napoca 48(1):503-508

DOI: $10.15835 /$ nbha48111795

Research Article

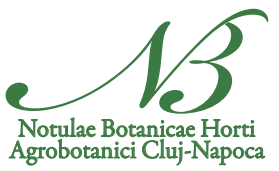

\title{
In vitro embryo rescue for the production of hypotetraploids after cross between hypotetraploid and tetraploid grape cultivars
}

\author{
Si-Hong KIM ${ }^{1}$, Joon-Ho KWON², Young-Sik PARK ${ }^{3}$, Jae-Yun $\mathrm{HEO}^{2 *}$
}

\author{
${ }^{1}$ Kangwon National University, Department of Horticulture, Chuncheon 24341, Korea; knu.shkim@gmail.com \\ ${ }^{2}$ Gangnueng-Wonju National University, Department of Plant Science, Gangnueng 25457, \\ Korea; horticulture@naver.com;jyheo@gwnu.ac.kr (*correspondingauthor) \\ ${ }^{3}$ Gangwon Provincial Agricultural Research and Extension Services, Chuncheon 24226, Korea; youngsik.park1968@gmail.com
}

\begin{abstract}
Consumer demand for seedless grape with high quality and large berry has been increasing. Breeding of hypotetraploid grape was suggested as one of promising methods to satisfy it, but low frequency of hypotetraploid occurrence and low seed germination by abortive embryo were indicated as the major problem to hamper the development of hypotetraploid grape. Hence, this study was carried out to evaluate the basic efficiency of in ovulo embryo culture after the cross between hypotetraploid ('Hanareum') and tetraploid ('Honey Black' and 'Kyoho') grape cultivars on the establishment of hypotetraploid grapes. Embryos and plantlets were hardly obtained in ovules cultured at six after the cross pollination (WAP), but ovules inoculated at $10 \mathrm{WAP}$ produced more embryos as well as plantlets regardless of cross combination. Furthermore, we found that embryo formation was not affected by the basal media in ovules cultured at six WAP, but utilization of specific medium can be more beneficial for embryo formation when ovules were cultured at 10 WAP. A total of 17 plants were obtained from ovules cultured at $10 \mathrm{WAP}$, and above $50 \%$ of plants were identified as hypotetraploid grapes. These results indicate that in vitro embryo rescue after cross pollination between hypotetraploid and tetraploid grape can enhance the efficiency for the breeding of hypotetraploid grapes.
\end{abstract}

Keywords: aneuploidy; ovule; seedless grape; tissue culture

\section{Introduction}

Breeding of seedless grapes with large berries is gaining importance because of the increase in consumer demand. Seedless grapes have been mainly developed by using characters of parthenocarpy, stenospermocarpy or triploidy found in grapes (Stout, 1936; Pratt, 1971; Heo et al., 2007). Recently, production of hypotetraploid ( $2 n=4 x-2$ or $4 x-1=74$ or 75$)$ grapes have also been suggested as as one of promising methods to develop seedless grapes with large berries. They exhibit growth characteristics as stable as those of tetraploid grapes, and they have extremely low fertility of pollen (Park et al., 2015). They, therefore, can produce large seedless fruits via a one-time treatment of gibberellic acid during the full blooming period.

It has been reported that hypotetraploid seedlings were obtained from cross, open, or self-pollination of tetraploid grapes (Park et al., 2010), but the extremely low frequency rate of hypotetraploid seedlings has been acted as the main problems in breeding of hypotetraploid grape cultivars. It was found that cross between 
504

hypotetraploid and tetraploid grapes generates hypotetraploids more easily compared to previously used breeding methods. However, low seed germination caused by abortive embryos after cross pollination has remained a problem that hinders the breeding of hypotetraploid grape cultivars (Park et al., 2016). In vitro embryo rescue technique has been successfully applied to generate hybrid seedlings that can hardly be obtained by artificial cross combination of grape cultivars such as stenospermic $\times$ stenospermic or tetraploid $\times$ diploid grapes (Liu et al., 2016; Jiao et al., 2018). It has been well known that several factors affect the efficiency of in vitro embryo rescue, but there is no information on in vitro embryo rescue system to generate hypotetraploid grapes. Hence, this study was conducted to investigate the effects of ovule removal age and media type for in vitro embryo rescue after cross pollination between hypotetraploid and tetraploid grape cultivars on the efficiency of embryo rescue and establishment of hypotetraploids.

\section{Materials and Methods}

\section{Plant materials}

The hypotetraploid $(2 n=4 x-1=75)$ grape cultivar, 'Hanareum' (HR) developed by our research team was used as a female parent (Park et al., 2020); and tetraploid $(2 n=4 x=76)$ grape cultivars, 'Honey Black' (HB) and 'Kyoho' (KH) were used as male parents. HB, HR, and $\mathrm{KH}$ were 9-year-old vines, grown in the research orchard of Gangwondo Agricultural Research and Extension Services at Chuncheon, Korea.

\section{Embryo rescue procedure}

Emasculation was carried out five days before anthesis, followed by immediate bagging of the inflorescence. Artificial cross was made using a cotton swab with pollens collected earlier from the male parents. The pollinated clusters from a cross combination of 'HR' $\times$ 'HB' and 'HR' $\times$ ' $\mathrm{KH}$ ' were collected at 6 and 10 weeks after cross pollination (WAP). Harvested immature fruits were soaked in $70 \%$ ethanol for $1 \mathrm{~min}$, following which they were soaked in $2 \%$ sodium hypochlorite containing one drop of Tween 20 for 15 min, and then rinsed four times with sterile distilled water. Three different basal media were tested to evaluate the effect of embryo formation and establishment of plants; ovule of more than two $\mathrm{mm}$ in length were cultured on Emershad and Ramming (ER), Murashige and Skoog (MS), and Nitsch and Nitsch (NN) media. $30 \mathrm{~g} \mathrm{l}^{-1}$ sucrose, $2.0 \mathrm{gl}^{-1}$ activated charcoal (AC) and $8.0 \mathrm{gl}^{-1}$ agar were added into all embryo formation medium. The $\mathrm{pH}$ of all media was adjusted to 5.7 prior to addition of agar and sterilized at $121^{\circ} \mathrm{C}$ for $15 \mathrm{~min}$. Each condition for embryo formation consisted of seven replications each with five ovules. After 8 weeks of in ovulo culture, the percentage of embryo formation was investigated, and then each ovule was incubated on Woody Plant (WP) medium supplemented with $1.0 \mu \mathrm{M}$ 6-benzyladenine, $30 \mathrm{gl}^{-1}$ sucrose, $2.0 \mathrm{gl}^{-1} \mathrm{AC}$ and $8.0 \mathrm{gl}^{-1}$ agar. All cultures were maintained at $20 \pm 1{ }^{\circ} \mathrm{C}$ under cool-white fluorescent lamps providing 16 -h photoperiod (Figure $1)$.

\section{Observation for occurrence frequency of hypotetraploids}

Plants established from ovules at $10 \mathrm{WAP}$ were transplanted to pots filled with a commercial substrate mix and perlite (1:1) contained in plastic sundae cups with lids, and were hardened by gradually lowering the humidity over a period of one month (Kwon et al., 2019). Hardened plants were transferred to a commercial substrate mix in $1 \mathrm{~L}$ plastic pots and maintained in the glasshouse. Chromosome observation in root tip cells from successfully established plants was performed according to the method described by Park et al. (1999). 

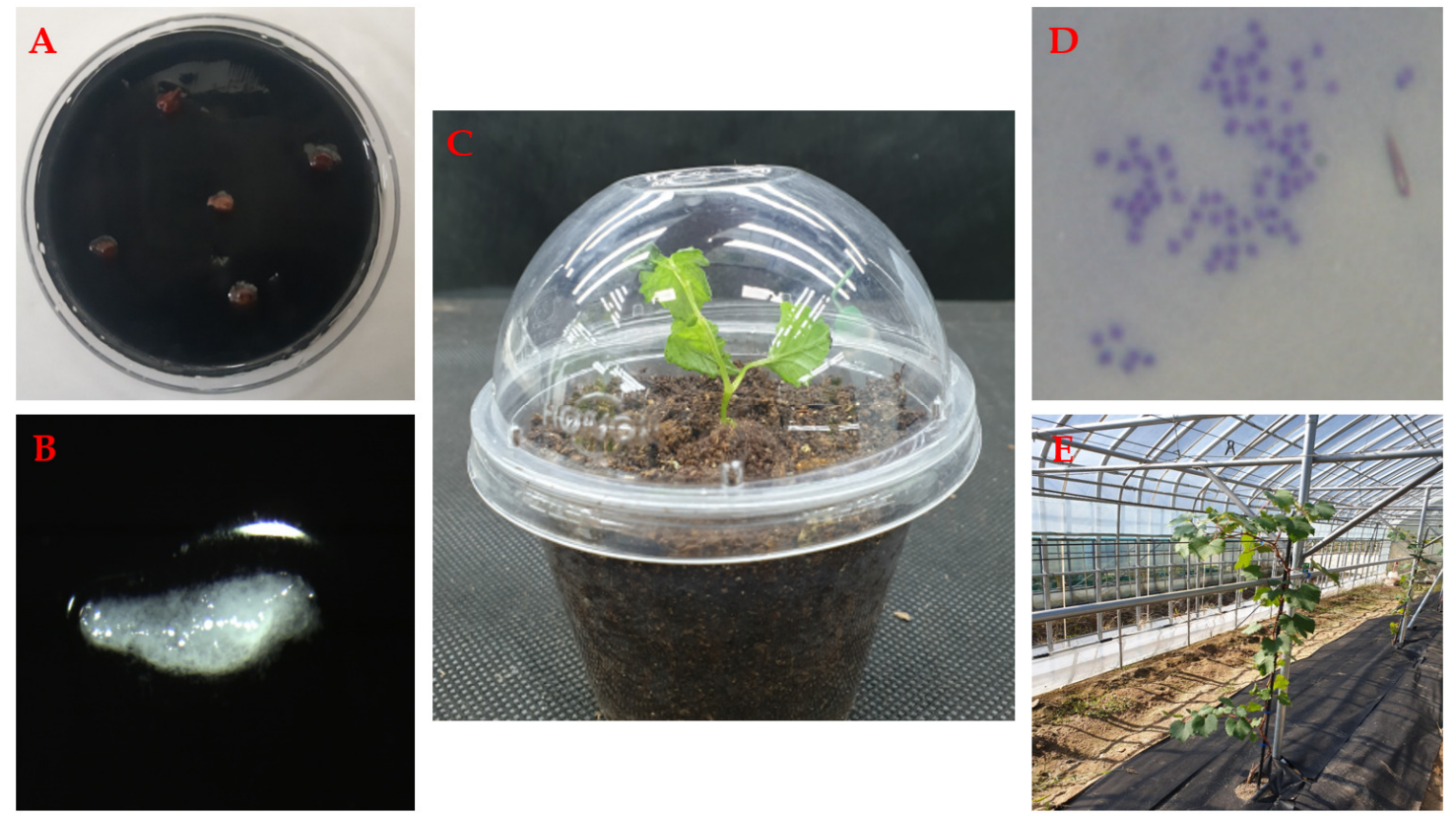

Figure 1. Embryo rescue procedure for production of hypotetraploid hybrid grapes. (A) ovules cultured in solid medium; (B) embryo cultured in solid medium; (C) whole plantlet developed from germinated embryos; (D) chromosome observation of hybrid seedling; (E) growth of seedlings identified as hypotetraploids in greenhouse

\section{Results and Discussion}

Efficiency of in vitro embryo rescue can be affected by several factors such as ovule removal age, basal medium, and genotype. Of these, removal age for ovule culture has been regarded as one of the most important factors. This is attributed to the fact that early culture, before the optimum ovule removal age, can result in imperfect development of the embryo. Similarly, extremely late culture, beyond the optimum ovule removal age, can cause abortion of the hybrid embryo or physiological dormancy (Guo et al., 2011). It has been reported that the optimum removal age for ovule culture usually ranges from 6 to $10 \mathrm{WAP}$ (Ji et al., 2013). In this study, only a few embryos and plants were obtained from ovules cultured at $6 \mathrm{WAP}$, whereas a higher number of embryos and plants were obtained from ovules inoculated at $10 \mathrm{WAP}$, regardless of cross combination, indicating that relatively late ovule culture can be efficient for cross combination. It has been suggested that the optimum removal age for ovule culture mainly depends on the maturity stage of the female parent (Table 1) (Yang et al., 2007). As 'HR' is a medium maturing grape cultivar, its $10 \mathrm{WAP}$ approximately coincides with its version; thus, our result was consistent with previous results.

The selection of a proper basal medium is regarded as another critical factor for in ovulo embryo culture of grapes because it is essential in promotion of embryo formation and prevention of embryo abortion. We observed that embryo formation in ovules cultured at $6 \mathrm{WAP}$ was not affected by basal media. However, utilization of specific medium can be beneficial for embryo formation based on a cross combination of ovules cultured at 10 WAP. NN and ER medium had the highest rate of embryo formation in ' $\mathrm{HR} \times \mathrm{HB}$ ' and ' $\mathrm{HR} \times$ $\mathrm{KH}^{\prime}$, respectively. It appeared that the use of $\mathrm{NN}$ and ER media resulted in the enhancement of nutrient absorption in ovules generated from ' $\mathrm{HR} \times \mathrm{HB}$ ' and ' $\mathrm{HR} \times \mathrm{KH}$ '. Similarly, research has already shown that the effect of basal medium on embryo formation varies among genotypes (Liu et al., 2003; Sun et al., 2011). These results indicate the importance of optimal basal medium selection in employing embryo rescue 
506

techniques in the production of hypotetraploid grapes. After transferring to WP medium, embryos that originated from ER and NN media showed the highest number of established plants, but many of them failed to germinate or produce root. Therefore, further research on the effect of plant hormones on germination and root formation of embryos is be needed to improve the efficiency of in vitro embryo rescue system for hypotetraploid production.

A total of 17 plants were established from ovules inoculated at $10 \mathrm{WAP}$ in ' $\mathrm{HR} \times \mathrm{HB}$ ' and ' $\mathrm{HR} \times \mathrm{KH}$ ', and their chromosome numbers were observed to range from $2 n=4 x-2=72$ to $2 n=4 x=76$ (Table 2). In ' $H R \times$ $\mathrm{HB}$, four plants were identified as tetraploids, and the other four plants were identified as hypotetraploids. Of the nine plants obtained from ' $\mathrm{HR} \times \mathrm{KH}$ ', five and four plants were found to be hypotetraploids and tetraploids, respectively. As a result, the frequency of occurrence of hypotetraploids ' $\mathrm{HR} \times \mathrm{HB}$ ' and ' $\mathrm{HR} \times \mathrm{KH}$ ' was calculated as $50.0 \%$ and $55.6 \%$, respectively.

Table 1. Effect of the time of ovule culture and basal medium on development of the embryos and in vitro growth of embryos excised after ovule culture

\begin{tabular}{|c|c|c|c|c|c|}
\hline \multirow{2}{*}{$\begin{array}{l}\text { Ovule age } \\
\text { (weeks) }\end{array}$} & \multirow{2}{*}{$\begin{array}{c}\text { Culture medium } \\
\text { used }\end{array}$} & \multicolumn{2}{|c|}{$\mathrm{HR} \times \mathrm{HB}$} & \multicolumn{2}{|c|}{$\mathrm{HR} \times \mathrm{KH}$} \\
\hline & & $\begin{array}{c}\text { No. of embryos } \\
\text { obtained (\%) }\end{array}$ & $\begin{array}{c}\text { No. of plants } \\
\text { established (\%) }\end{array}$ & $\begin{array}{c}\text { No. of embryos } \\
\text { obtained (\%) }\end{array}$ & $\begin{array}{c}\text { No. of plants } \\
\text { established (\%) }\end{array}$ \\
\hline \multirow{3}{*}{6} & ER & $7(20.0)^{\mathrm{ab}}$ & $1(2.9)^{\mathrm{ab}}$ & $7(20.0)^{\mathrm{b}}$ & $1(2.9)^{\mathrm{b}}$ \\
\hline & MS & $6(17.1)^{b}$ & $0(0.0)^{b}$ & $7(20.0)^{\mathrm{b}}$ & $0(0.0)^{\mathrm{b}}$ \\
\hline & NN & $6(17.1)^{b}$ & $0(0.0)^{b}$ & $8(22.9)^{b}$ & $1(2.9)^{\mathrm{b}}$ \\
\hline \multirow{3}{*}{10} & ER & $10(28.6)^{\mathrm{ab}}$ & $3(8.6)^{\mathrm{ab}}$ & $15(42.9)^{a}$ & $5(14.3)^{a}$ \\
\hline & MS & $8(22.9)^{a b}$ & $1(2.9)^{\mathrm{ab}}$ & $10(28.6)^{a b}$ & $1(2.9)^{\mathrm{b}}$ \\
\hline & $\mathrm{NN}$ & $11(31.4)^{\mathrm{a}}$ & $4(11.4)^{\mathrm{a}}$ & $12(34.3)^{a b}$ & $3(8.6)^{\mathrm{ab}}$ \\
\hline
\end{tabular}

Note: Means followed by the same letter within each column are not significantly different at P0.05.

Table 2. Chromosome number in plants obtained from ovules inoculated at $10 \mathrm{WAP}$

\begin{tabular}{|c|c|c|c|c|c|c|c|}
\hline \multirow{2}{*}{$\begin{array}{c}\text { Cross } \\
\text { combination }\end{array}$} & \multirow{2}{*}{$\begin{array}{l}\text { Culture } \\
\text { medium } \\
\text { used }\end{array}$} & \multirow{2}{*}{$\begin{array}{l}\text { No. of } \\
\text { plants }\end{array}$} & \multicolumn{4}{|c|}{ Chromosome number } & \multirow{2}{*}{$\begin{array}{c}\text { Frequency of } \\
\text { hypotetraploids } \\
(\%)\end{array}$} \\
\hline & & & $\begin{array}{c}2 n=4 x- \\
4=72\end{array}$ & $\begin{array}{r}2 n=4 x- \\
2=74\end{array}$ & $\begin{array}{c}2 n=4 x- \\
1=75\end{array}$ & $2 n=4 x=76$ & \\
\hline \multirow{3}{*}{$\mathrm{HR} \times \mathrm{HB}$} & ER & 3 & 1 & - & 1 & 1 & 66.7 \\
\hline & MS & 1 & & - & - & 1 & 0.0 \\
\hline & $\mathrm{NN}$ & 4 & & 1 & 1 & 2 & 50.0 \\
\hline \multirow{3}{*}{$\mathrm{HR} \times \mathrm{KH}$} & ER & 5 & & 1 & 2 & 2 & 60.0 \\
\hline & MS & 1 & & - & - & 1 & 0.0 \\
\hline & $\mathrm{NN}$ & 3 & & 1 & 1 & 1 & 66.7 \\
\hline
\end{tabular}

Previously, 52 mature seeds were obtained from diverse artificial crosses using 'HR' as a female parent (Park, 2005), but only two germinated seedlings, including one hypotetraploid seedling, were obtained. Apart from this fact, we observed that hypotetraploid seedlings obtained from in vitro embryo rescue showed stable vine growth. These results suggest that applying in vitro embryo rescue techniques based on a well-developed protocol after a cross between hypotetraploid and tetraploid grapes can improve the efficiency of production of hypotetraploid grape hybrids. Further effort to improve the protocol of in vitro embryo rescue using a greater number of genotypes for the production of hypotetraploids will facilitate the development of new seedless grape varieties with large berries. 


\section{Conclusions}

In this study, we investigated the effects of ovule removal age and media type for in vitro embryo rescue after cross pollination between hypotetraploid and tetraploid grape cultivars on the efficiency of embryo rescue and establishment of hypotetraploids. As a result, we found that efficiency of in vitro embryo rescue was affected by ovule removal age, basal medium and cross combination, and specific condition for in vitro embryo rescue can be helpful for production of hypotetraploids.

\section{Acknowledgements}

This work was supported by the National Research Foundation of Korea (NRF) grant funded by the Korea government (MSIT) (No. 2017R1C1B2008589).

\section{Conflict of Interests}

The authors declare that there are no conflicts of interest related to this article.

\section{References}

Guo Y, Zhao Y, Li K, Liu Z, Lin H, Guo X, Li C (2011). Embryo rescue of crosses between diploid and tetraploid grape cultivars and production of triploid plants. African Journal of Biotechnology 10:19005-19010.

Heo JY, Park KS, Yun HK, Park SM (2007). Degree of abortion and germination percentage in seeds derived from interploid crosses between diploid and tetraploid grape cultivars. Horticulture, Environment, and Biotechnology 48:115-121.

Ji W, Li ZQ, Zhou Q, Yao WK, Wang YJ (2013). Breeding new seedless grape by means of in vitro embryo rescue. Genetics and Molecular Research 12:859-869.

Jiao Y, Li Z, Xu K, Guo Y, Zhang C, Li T, ... Xu Y (2018). Study on improving plantlet development and embryo germination rates in in vitro embryo rescue of seedless grapevine. New Zealand Journal of Crop and Horticultural Science 46:39-53.

Kwon JH, Park YS, Kim SH, Heo JY (2019). Evaluation of genetic stability and effects of plant growth regulators for in vitro propagation of underutilized Vitis amurensis 'Cheongsan'. Notulae Botanicae Horti Agrobotanici Cluj-Napoca 47:987994.

Liu Q, Zhang J, Wang Y, Yu D, Xia H (2016). Breeding for cold-resistant, seedless grapes from Chinese wild Vitis amurensis using embryo rescue. New Zealand Journal of Crop and Horticultural Science 44:136-151.

Liu SM, Sykes SR, Clingeleffer PR (2003). Improved in ovulo embryo culture for stenospermocarpic grapes (Vitis vinifera L.). Australian Journal of Agricultural Research 54:869-876.

Park SM, Hiramatsu M, Wakana A (1999). Aneuploid plants derived from crosses with triploid grapes through immature seed culture and subsequent embryo culture. Plant Cell, Tissue and Organ Culture 59:125-133.

Park YS (2005). Establishment of breeding system of large and seedless fruit through production of hypo-and hyper-tetraploid in vitis complex. Ph D diss., Kangwon National University, Chuncheon, Korea.

Park YS, Heo JY, Park SM (2016). Production of hypo-and hypertetraploid seedlings from open-, self-, and cross-pollinated hypo-and hypertetraploid grape. Horticultural Science \& Technology 34:771-778

Park YS, Heo JY, Um NY, Bang SB, Park SM (2015). Growth and fruit characteristics of hypo-, hyper-tetraploid grapes. Korean Journal of Breeding Science 47:192-198.

Park YS, Kim IJ, Park SM (2010). Selection of hypo-and hyper-tetraploid seedlings from abnormal cotyledons seedlings obtained during crossing of tetraploid grapes (Vitis complexes). Horticultural Science \& Technology 28:810-817.

Park YS, Lim YS, Heo JY (2020). ‘Hanareum' grape. HortScience 55(2):275-276. 
Kim SH et al. (2020). Not Bot Horti Agrobo 48(1):503-508.

508

Pratt C (1971). Reproductive anatomy in cultivated grapes-a review. American Journal of Enology and Viticulture 22:92-109.

Stout AB (1936). Seed lessness in grapes. New York State Agricultural Experiment Station Geneva. N.Y. no. 238.

Sun L, Zhang GJ, Yan AL, Xu HY (2011). The study of triploid progenies crossed between different ploidy grapes. African Journal of Biotechnology 10:5967-5971.

OPEN ACCESS

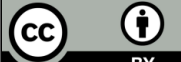

The journal offers free, immediate, and unrestricted access to peer-reviewed research and scholarly work. Users are allowed to read, download, copy, distribute, print, search, or link to the full texts of the articles, or use them for any other lawful purpose, without asking prior permission from the publisher or the author.

License - Papers published in Notulae Botanicae Horti Agrobotanici Cluj-Napoca are Open-Access, distributed under the terms and conditions of the Creative Commons Attribution (CC BY) License.

(c) Articles by the authors; UASVM, Cluj-Napoca, Romania. The journal allows the author(s) to hold the copyright/to retain publishing rights without restriction. 